\title{
PENGARUH KEAKTIFAN MENGIKUTI \\ ORGANISASI SISWA INTRA SEKOLAH (OSIS) \\ TERHADAP HASIL BELAJAR PENDIDIKAN AGAMA \\ ISLAM (PAI) DI BENGKULU
}

\section{Pasmah Chandra, Wilda Tri Kartika}

IAIN Bengkulu

pasmah@iainbengkulu.ac.id,wildakartika@gmail.com

\begin{tabular}{|c|c|}
\hline \multicolumn{2}{|r|}{ Abstrak } \\
\hline $\begin{array}{l}\text { Article History } \\
\text { Received: } 18-01-2021 \\
\text { Revised : 21-01-2021 } \\
\text { Accepted:27-01-2021 } \\
\text { Keywords: } \\
\text { Activeness Following } \\
\text { Intra School } \\
\text { Organizations, } \\
\text { Learning Outcomes }\end{array}$ & $\begin{array}{l}\text { This study aims to determine the effect } \\
\text { of active participation in the Intra } \\
\text { School Student Organization (OSIS) on } \\
\text { student learning outcomes in the subject } \\
\text { of Islamic Religious Education at SMA } \\
\text { Negeri 09 Bengkulu City. This type of } \\
\text { research is a quantitative study with an } \\
\text { associative quantitative approach. Test } \\
\text { the validity of the instrument using } \\
\text { SPSS16 with Product Moment } \\
\text { Correlation and reliability also using } \\
\text { SPSS16 with Cronbach's Alpha. The } \\
\text { results showed that the activeness of } \\
\text { intra-school organizations had an effect } \\
\text { on student learning outcomes. This is } \\
\text { evidenced by the t count of } 2.981 \text { while } \\
\text { the t table of } 2.064 \text { at the significant } \\
\text { level of } 0.05 \text {. Based on these results } t \\
\text { count is greater than table. So it can be } \\
\text { concluded that Ha is accepted and Ho is } \\
\text { rejected so that there is an effect of } \\
\text { active participation of intra-school } \\
\text { organizations on student learning } \\
\text { outcomes by } 4 \% \text { while the remaining } \\
96 \% \text { is influenced by other factors not } \\
\text { examined in this study. This can be seen } \\
\text { from the value of R Square. }\end{array}$ \\
\hline
\end{tabular}




\section{Pendahuluan}

Pembelajaran ialah sesuatu proses ataupun aktivitas yang ditunjukan buat mengganti prilaku manusia (Humanbehavior). (Jenilan, 2018) Perilaku yang dimaksud berupa setiap tanggapan atau perbuatan seseorang.(Budiman, 2017) Undang-undang No. 20 Tahun 2003 Pasal 1 Tentang Sistem Pendidikan Nasional (Sisdiknas), disebutkan bahwa: "Pendidikan adalah usaha sadar dan terencana untuk mewujudkan suasana belajar dan proses pembelajaran agar peserta didik secara aktif mengembangkan potensi dirinya untuk memiliki kekuatan spiritual keagamaan, pengendalian diri, kepribadian, kecerdasan, akhlak mulia, serta keterampilan yang diperlukan dirinya, masyarakat, bangsa, dan negara".(Kemendikbud, 2013)

Sesuai dengan Undang-Undang Sisdiknas yang telah dipaparkan diatas, bahwa pendidikan bertujuan untuk membentuk kecerdasan siswa yang dapat dilihat melalui hasil belajar. Pembelajaran sanggup meningkatkan kemampuan diri, kecerdasan, akhlak serta aspek lain yang terdapat pada diri seorang. Untuk mendapatkan ilmu pengetahuan tersebut membutuhkan orang lain sebagai mediator penyampaiannya. Seperti di jelaskan dalam Q.S AlMujadalah ayat 11:

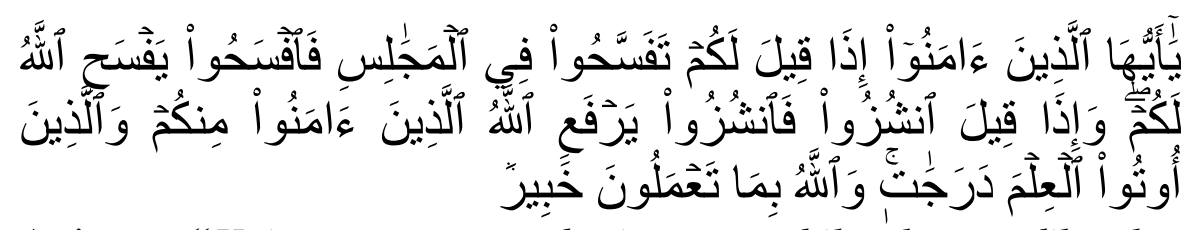

Artinya :"Hai orang-orang beriman apabila kamu dikatakan kepadamu: "Berlapang-lapanglah dalam majlis", Maka lapangkanlah niscaya Allah akan memberi kelapangan untukmu. dan apabila dikatakan: "Berdirilah kamu", Maka berdirilah, niscaya Allah akan meninggikan orang-orang yang beriman di antaramu dan orang-orang yang diberi ilmu pengetahuan beberapa derajat. dan Allah Maha mengetahui apa yang kamu kerjakan".

Berdasarkan ayat diatas, Allah SWT sangat menegaskan akan pentingnya menuntut ilmu agar tercapainya tujuan dalam kehidupan. Ilmu tersebut dapat diperoleh melalui proses pendidikan. Manusia yang memiliki ilmu pengetahuan dapat membedakan antara hal yang baik dan hal yang buruk. Pada teori belajar kognitivisme, belajar 
merupakan pengorganisasian aspek- aspek kognitif buat mendapatkan uraian. Tujuan serta tingkah laku sangat dipengaruhi oleh proses berfikir internal yang terjalin sepanjang proses belajar.

Bagi Piaget dalam makalah Widya Wati, manusia berhadapan dengan tantangan, pengalaman, serta perkara yang wajib ditanggapinya secara kognitif (mental). (Marhayati et al., 2020) Buat itu, manusia wajib meningkatkan skema benak lebih universal ataupun rinci, ataupun butuh pergantian, menanggapi serta menginterpretasikan pengalaman- pengalaman tersebut.

Berdasarkan teori tersebut, tujuan belajar ialah untuk mencapai pengetahuan kognitif yang dapat dilihat dari hasil belajar. Hasil belajar adalah kemampuan yang diperoleh anak setelah melalui kegiatan pembelajaran. (Chandra, 2020)Hasil belajar siswa pada hakikatnya adalah perubahan tingkah laku sebagai hasil belajar dalam pengertian yang lebih luas mencakup bidang kognitif, afektif, dan psikomotorik.(Aziz et al., 2017) Hasil belajar merupakan hasil dari suatu interaksi tindak belajar dan tindak mengajar. Hasil belajar pada umumnya dipengaruhi oleh dua faktor utama yaitu faktor internal dan faktor eksternal..(Ricardo \& Meilani, 2017) Faktor internal (faktor yang berasal dari dalam diri), meliputi kesehatan, intelegensi dan bakat, minat dan motivasi, dan cara belajar. Faktor eksternal (faktor yang berasal dari luar diri), meliputi keluarga, sekolah, masyarakat, dan lingkungan sekitar.(Syafi'i et al., 2018)

Menurut Hamalik dalam Kunandar menarangkan kalau hasil belajar merupakan pola- pola perbuatan, nilai- nilai, pengertianpengertian, serta sikap- sikap dan keahlian partisipan didik. Sebaliknya Sudjana berkomentar kalau hasil belajar merupakan kemampuan- kemampuan yang dipunyai partisipan didik sehabis menerima pengalaman belajarnya.(Kunandar, 2015)

Salah satu faktor yang dapat mempengaruhi hasil belajar siswa ialah melalui minat mengikuti kegiatan organisasi. Salah satunya yakni organisasi yang terletak di sekolah merupakan Organisasi Siswa Intra Sekolah (OSIS). Organisasi siswa intra sekolah (OSIS) merupakan sesuatu organisasi yang terletak di tingkatan sekolah di Indonesia yang diawali dari Sekolah Menengah Awal (SMP) serta Sekolah Menengah Atas (SMA). OSIS diurus serta dikelola oleh murid- murid yang terpilih buat jadi pengurus OSIS. (Sobirin, 2014) Umumnya organisasi ini mempunyai seseorang pembimbing dari guru yang diseleksi oleh pihak sekolah. Anggota 
OSIS merupakan segala siswa yang terletak pada satu sekolah tempat OSIS itu terletak

Kegiatan OSIS diharapkan mampu mendorong keberhasilan belajar siswa. Salah satu hasil belajar yang diharapkan mampu meningkat melalui keaktifan mengikuti kegiatan OSIS ini ialah mata pelajaran pendidikan agama Islam. PAI adalah usaha yang dapat direaliskan untuk melengkapkan pelajar dalam meyakinkan, memahami, menghargai, dan mengamalkan agama Islam melalui bimbingan, mengarahkan atau menjalankan aktiviti dengan memerhati tuntutan untuk menghormati agama lain selaras dengan orang-orang agama dalam masyarakat untuk mewujudkan kesatuan kebangsaan. (Nafeesa, 2018)

Namun, pada kenyataannya ini tidak selalu memiliki efek positif seperti yang diharapkan. Siswa yang selalu aktif dalam kegiatan dewan siswa, di satu sisi akan mengurangi waktu studi. Apalagi jika siswa ini tidak memiliki manajemen waktu yang baik.

Data awal di Sekolah Menengah Atas Negeri 09 Kota Bengkulu terdapat siswa yang lebih memilih aktif mengikuti organisasi OSIS dan terdapat juga siswa yang banyak ketinggalan materi pembelajaran serta kelelahan dalam belajar karena terlalu sibuk mengikuti kegiatan OSIS. Dari observasi tersebut terdapat jumlah anggota OSIS di Sekolah Menengah Atas Negeri 09 Kota Bengkulu sebanyak 25 orang yang merupakan perwakilan dari tiaptiap kelasnya dari kelas X-XII. OSIS di Sekolah Menengah Atas Negeri 09 Kota Bengkulu memiliki beberapa agenda tahunan seperti Masa Orientasi Siswa (MOS), class metting, PHBI dan perpisahan sekolah. Dalam agenda itu selalu melibatkan semua anggota dewan siswa dan siswa dan guru lainnya. Mos dan kelas Metting berada di luar dalam belajar karena itu adalah agenda awal dan akhir semester, tetapi untuk peringatan hari besar atau agenda tertentu terjadi pada satu semester dan sangat memanfaatkan waktu pembelajaran.

\section{Metode Penelitian}

\section{Jenis Penelitian}

Jenis penelitian ini adalah penelitian kuantitatif asosiatif. Ini adalah penelitian yang bertujuan untuk mengetahui efek atau hubungan antara dua atau lebih variabel. Dengan penelitian ini, sebuah teori akan dibangun yang dapat berfungsi untuk menjelaskan, 
memprediksi, dan mengendalikan gejala dalam penelitian ini.(Harahap \& Lubis, 2019)

\section{Populasi dan Sampel}

Populasi pada penelitian ini adalah siswa yang mengikuti Organisasi Siswa Intra Sekolah (OSIS) di Sekolah Menengah Atas Negeri 09 Kota Bengkulu sebanyak 25 orang. Teknik pengambilan sampel dalam penelitian ini dengan mengunakan teknik Purposive Samplingadalah teknik penentuan sampel dengan pertimbangan tertentu.(Crossman, 2020) Suharsimi Arikunto menyatakan bahwa "apabila subjek penelitian (populasi) kurang dari seratus orang, maka lebih baik di ambil seluruhnya, akan tetapi jika subjeknya lebih dari seratus orang, maka lebih baik diambil sekitar $10 \%-15 \%$ atau $20 \%$ 25\%. Dari penjelasan di atas maka, peneliti mengambil sampel seluruh dari jumlah populasi yang jumlahnya 25 orang.

\section{Teknik Pengumpulan Data}

Saat peneliti melakukan penelitian di Sekolah Menengah Atas Negeri 09 Kota Bengkulu pada bulan Januari hingga Februari 2020. Melalui izin pihak sekolah serta bantuan dari pembina OSIS peneliti dapat melakukan penelitian dengan cara mengumpulkan seluruh anggota OSIS di Sekolah Menengah Atas Negeri 09 Kota Bengkulu agar dapat mengisi angket yang telah disiapkan oleh peneliti. Ada beberapa instrumen pengumpulan data yang akan digunakan dalam penelitian ini, diantaranya:

\section{Angket (kuesioner)}

Kuesioner ini digunakan bertujuan untuk mendapatkan data yang berkaitan dengan efek mengaktifkan organisasi siswa intrasekolah (OSIS) pada hasil belajar siswa dalam mata pelajaran pendidikan agama Islam di Sekolah Menengah Kota Bengkulu. Kuesioner yang digunakan dalam penelitian ini dilakukan melalui beberapa tahap, yaitu:

\section{Dokumentasi}

Dalam hal ini, dokumentasi digunakan untuk mengambil dan mengumpulkan data yang bersumber dari dokumen dan keterangan yang ada di Sekolah Menengah Atas Negeri 09 Kota Bengkulu. 


\section{Observasi}

Observasi ini dilakukan sebagai langkah awal dalam mengamati fenomena sosial di Sekolah Menengah Atas Negeri 09 Kota Bengkulu.

\section{Teknik Analisis Data}

\section{Hipotesis Statistik}

Hipotesis statistik merupakan pernyataan atau dugaan mengenai keadaan populasi yang sifatnya masih sementara atau lemah tingkat kebenarannya.(Sugiyono, 2016) Untuk mengetahui apakah hipotesis diterima atau ditolak, maupun ada tidaknya hubungan antara dua variabel. Maka akan digunakan uji t. Analisis uji t (t test) ini digunakan untuk mengetahui signifikasi variabel independen (X) terhadap variabel dependen (Y) secara individual.

\section{a. Pengujian Hipotesis}

$\mathrm{Ha}$ :"Adanya pengaruh Keaktifan Mengikuti Organisasi Siswa Intra Sekolah (OSIS) Terhadap Hasil Belajar Siswa Pada Mata Pelajaran Pendidikan Agama Islam Di Sekolah Menengah Atas Negeri 09 Kota Bengkulu"

Ho :"TidakAdanya pengaruhKeaktifan Mengikuti Organisasi Siswa Intra Sekolah (OSIS) Terhadap Hasil Belajar Siswa Pada Mata Pelajaran Pendidikan Agama Islam Di Sekolah Menengah Atas Negeri 09 Kota Bengkulu"

\section{b. Menentukan Tingkat Signifikan}

Tingkat Signifikan $(\alpha)=5 \%$, derajat kebebasan $(\mathrm{dk})=\mathrm{n}-1$. Untuk mencari nilai $t_{\text {tabel }}$ dapat dilihat dari tabel nilai $t_{\text {tabel. }}$ Untuk mencari nilai $t_{\text {hitung }}$ menggunakan rumus:(Sugiyono, 2018)

Kriteria Pengujian

$$
t=\frac{r \sqrt{n-2}}{\sqrt{1-r^{2}}}
$$

$t_{\text {hitung }}>t_{\text {tabel }}$ : maka menolak hipotesis nol (Ho) yang secara statistik menyimpulkan bahwa variabel independent $(\mathrm{X})$ berpengaruh signifikan terhadap variabel dependen (Y).

$t_{\text {hitung }}<t_{\text {tabel }}$ : maka menerima hipotesis nol (Ho) yang secara statistik menyimpulkan bahwa variabel independent (X) 
tidak berpengaruh signifikan terhadap variabel dependen $(\mathrm{Y})$.

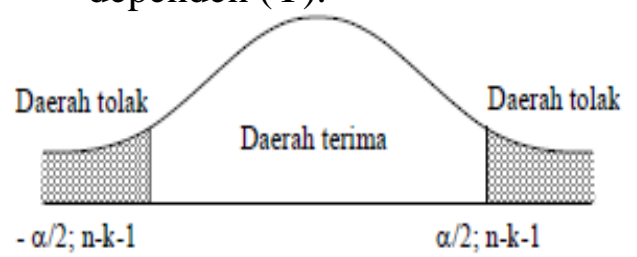

Kesimpulan

$\mathrm{Ha}=$ apabila $\mathrm{t}_{\text {hitung }}>\mathrm{t}_{\text {tabel }}$

$\mathrm{H}_{0}=$ apabila $\mathrm{t}_{\text {hitung }}<\mathrm{t}_{\text {tabel }}$

\section{Pembahasan}

\section{Analisis Data}

a. Uji Prasyarat

Sebelum menguji hipotesis penelitian dengan uji regresi linier sederhana, tes prasyarat analisis data terdiri dari uji normalitas dan uji linearitas.(Riadi, 2016)

1) Uji Normalitas

Uji normalitas untuk mengetahui apakah variabel, secara independen atau keduanya biasanya didistribusikan dalam arti dekat dengan normal atau tidak, dalam hal ini menggunakan tes Kolmogorov-Smirnov. (Putrana et al., 2016) Adapun hasil dari perhitungannya menggunakan SPSS16 dapat terlihat pada tabel berikut ini:

Tabel 1

Uji Normalitas

One-Sample Kolmogorov-Smirnov Test

\begin{tabular}{|ll|r|}
\hline & & $\begin{array}{r}\text { Unstandardiz } \\
\text { ed Residual }\end{array}$ \\
\hline N & & 25 \\
Normal Parameters $^{\mathrm{a}}{ }^{2}$ & Mean & .0000000 \\
& Std. Deviation & 2.03789892 \\
Most Extreme & Absolute & .122 \\
Differences & Positive & .122 \\
& Negative & .089 \\
Kolmogorov-Smirnov Z & .609 \\
Asymp. Sig. (2-tailed) & .852 \\
\hline
\end{tabular}


182 Pasmah dan Wilda, Pengaruh Keaktifan Mengikuti,...

One-Sample Kolmogorov-Smirnov Test

\begin{tabular}{|ll|r|}
\hline & & $\begin{array}{l}\text { Unstandardiz } \\
\text { ed Residual }\end{array}$ \\
\hline $\mathrm{N}$ & 25 \\
Normal Parameters $^{\mathrm{a}}$ & Mean & .0000000 \\
& Std. Deviation & 2.03789892 \\
Most Extreme & Absolute & .122 \\
Differences & Positive & .122 \\
& Negative & .089 \\
Kolmogorov-Smirnov Z & .609 \\
Asymp. Sig. (2-tailed) & .852 \\
\hline a. Test distribution is Normal. & \\
Sumber: SPSS16.0 &
\end{tabular}

Berdasarkan data di atas diketahui bahwa nilai signifikan sebesar 0,852 lebih besar dari taraf signifikan 0,05 atau 5\% yang berarti Ho ditolak dan Ha diterima sehingga dapat disimpulkan bahwa data yang diuji berdistribusi normal.

\section{2) Uji Linieritas}

Tes linearitas digunakan untuk menentukan apakah variabel independen $(\mathrm{X})$ dan variabel terikat $(\mathrm{Y})$ memiliki hubungan linear atau tidak dengan melihat tabel output tabel ANOVA sebagai berikut:

Tabel 2

Uji Linieritas

Sumber: SPSS16.0

ANOVA Table

\begin{tabular}{|c|c|c|c|c|c|c|c|}
\hline & & & $\begin{array}{l}\text { Sum of } \\
\text { Squares }\end{array}$ & Df & $\begin{array}{l}\text { Mean } \\
\text { Square }\end{array}$ & $\mathrm{F}$ & Sig. \\
\hline \multirow[t]{5}{*}{$\mathrm{Y} * \mathrm{X}$} & \multirow{3}{*}{$\begin{array}{l}\text { Between } \\
\text { Groups }\end{array}$} & & 30.507 & 14 & 2.179 & .297 & .981 \\
\hline & & Linearity & 4.167 & 1 & 4.167 & .568 & .468 \\
\hline & & $\begin{array}{l}\text { Deviation from } \\
\text { Linearity }\end{array}$ & 26.339 & 13 & 2.026 & .276 & .983 \\
\hline & \multicolumn{2}{|c|}{ Within Groups } & 73.333 & 10 & 7.333 & & \\
\hline & \multicolumn{2}{|l|}{ Total } & 103.840 & 24 & & & \\
\hline
\end{tabular}


Dasar pengambilan keputusan dalam uji linieritas dapat dilakukan dengan dua cara yakni melihat nilai signifikasi dan nilai $\mathrm{F}$.

a) Berdasarkan nilai signifikasi (sig): dari output diatas, diperoleh nilai Deviation From Linearity Sig. Adalah 0,983 lebih besar dari 0,05. Maka dapat disimpulkan bahwa ada hubungan linier secara signifikan antara variabel Keaktifan Mengikuti Organisasi Siswa Intra Sekolah (OSIS) (X) dengan variabel Hasil Belajar (Y).

b) Berdasarkan nilai $F$ : dari output diatas, diperoleh nilai $F_{\text {hitung }}$ adalah 0,276, sedangkan $F_{\text {tabel }}$ dengan dk pembilang 25-1 = 24 dan dk penyebut $25-2=23$. Maka nilai $F_{\text {tabel }}=2,00$. Jadi $F_{\text {hitung }}<$ $\mathrm{F}_{\text {tabel }}=0,276<2,00$ maka dapat disimpulkan bahwa ada hubungan linier secara signifikan variabel Mengikuti Organisasi Siswa Intra Sekolah (OSIS) (X) dengan variabel Hasil Belajar (Y).

\section{Hasil Uji Hipotesis}

b. Uji Regresi Linier Sederhana

Analisis regresi linier sederhana digunakan untuk menguji pengaruh satu variabel bebas atau variabel independen terhadap variabel terikat atau dependen. Adapun hasil dari perhitungannya menggunakan SPSS16 dapat terlihat pada tabel berikut ini:

Tabel 3

Hasil Analisis Regresi Linier Sederhana

ANOVA Table

\begin{tabular}{|c|c|c|c|c|c|c|c|}
\hline & & & $\begin{array}{l}\text { Sum of } \\
\text { Squares }\end{array}$ & df & $\begin{array}{l}\text { Mean } \\
\text { Square }\end{array}$ & $\mathrm{F}$ & Sig. \\
\hline \multirow{5}{*}{$\begin{array}{l}Y^{*} \\
\mathrm{X}\end{array}$} & \multirow{3}{*}{$\begin{array}{l}\text { Between } \\
\text { Groups }\end{array}$} & (Combined) & 30.507 & 14 & 2.179 & .297 & .981 \\
\hline & & Linearity & 4.167 & 1 & 4.167 & .568 & .468 \\
\hline & & $\begin{array}{l}\text { Deviation from } \\
\text { Linearity }\end{array}$ & 26.339 & 13 & 2.026 & .276 & .983 \\
\hline & \multicolumn{2}{|c|}{ Within Groups } & 73.333 & 10 & 7.333 & & \\
\hline & \multicolumn{2}{|l|}{ Total } & 103.840 & 24 & & & \\
\hline
\end{tabular}

Berdasarkan tabel diatas, uji regresi tentang pengaruh keaktifan mengikuti Organisasi Siswa Intra Sekolah (OSIS) terhadap hasil belajar siswa di Sekolah Menengah Atas Negeri 09 Kota Bengkulu menunjukkan nilai $F_{\text {hitung }}$ sebesar 0,276. Nilai $F_{\text {hitung jika }}$ dikonsultasikan dengan $\mathrm{F}_{\text {tabel }}=2,00$, maka $\mathrm{F}_{\text {hitung }}<\mathrm{F}_{\text {tabel }}$. Hal ini 
menunjukkan bahwa hipotesis yang berbunyi ada pengaruh keaktifan mengikuti Organisasi Siswa Intra Sekolah (OSIS) terhadap hasil belajar siswa di Sekolah Menengah Atas Negeri 09 Kota Bengkulu diterima dan signifikan.

c. Uji Koefisien Determinasi $(R 2)$

Tabel 4

Hasil Uji Koefisien Determinasi

\begin{tabular}{|c|c|c|c|c|}
\hline Model & $\mathrm{R}$ & R Square & $\begin{array}{l}\text { Adjusted R } \\
\text { Square }\end{array}$ & $\begin{array}{l}\text { Std. Error of the } \\
\text { Estimate }\end{array}$ \\
\hline 1 & $.200^{\circ}$ & .040 & .002 & 2.082 \\
\hline
\end{tabular}

a. Predictors: (Constant), $\mathrm{X}$

Berdasarkan pada tabel summary, bahwa nilai R Square Keaktifan Mengikuti Organisasi Siswa Intra Sekolah sebesar 0,040 atau 4\%. Dengan adanya nilai R Square tersebut dijelaskan bahwa hasil belajar siswa dipengaruhi oleh Keaktifan Mengikuti Organisasi Siswa Intra Sekolah sebesar 4\% sementara sisanya 96\% dipengaruhi oleh faktor lain yang tidak diteliti dalam penelitian ini.

\section{d. Uji Koefisien Regresi Linier Sederhana}

Uji T digunakan untuk mengetahui apakah dalam model regresi pada jika keaktifan mengikuti Organisasi Siswa Intra Sekolah (X) berpengaruh signifikan terhadap hasil belajar siswa (Y). Dengan hipotesis penelitian:

Ha : Adanya pengaruh yang signifikan keaktifan mengikuti Organisasi Intra

Sekolah (X) terhadap hasil belajar siswa (Y).

Ho : Tidak ada pengaruh yang signifikan signifikan keaktifan Mengikut Organisasi Siswa Intra Sekolah (X) terhadap hasil belajar siswa (Y). 
Tabel 5

Koefisien Regresi Linier Sederhana

Coefficients $^{\mathrm{a}}$

\begin{tabular}{|c|c|c|c|c|c|}
\hline \multirow[b]{2}{*}{ Model } & \multicolumn{2}{|c|}{\begin{tabular}{|l|} 
Unstandardized \\
Coefficients
\end{tabular}} & \multirow{2}{*}{\begin{tabular}{|l|}
$\begin{array}{l}\text { Standardized } \\
\text { Coefficients }\end{array}$ \\
Beta \\
\end{tabular}} & \multirow[b]{2}{*}{$\mathrm{T}$} & \multirow[b]{2}{*}{ Sig. } \\
\hline & B & Std. Error & & & \\
\hline $\begin{array}{ll}1 & \text { (Constant } \\
& )^{2}\end{array}$ & 88.835 & 3.852 & & 23.063 & .000 \\
\hline$X$ & .039 & .040 & .200 & 2.981 & .337 \\
\hline
\end{tabular}

a. Dependent Variable: $\mathrm{Y}$

Berdasarkan tabel diatas, diperoleh persamaan regresi linier sederhana yaitu:

$\mathrm{Y}=\mathrm{a}+\mathrm{bX}$

$\mathrm{Y}=88,835+0,39 \mathrm{X}$

$\mathrm{Y}=88,835+0,39 \mathrm{X}$

Hasil perhitungan yang telah dilakukan menghasilkan suatu persamaan yang menunjukkan besarnya nilai $\mathrm{X}$ merupakan regresi yang diestimasikan sebagai berikut:

1) Harga konstanta (a) sebesar 88,835 artinya variabel $X$ (keaktifan mengikuti Organisasi Siswa Intra Sekolah) $=0$ (harga konstan), maka variabel Y (Hasil Belajar Siswa) nilainya sebesar 88,835.

2) Adapun koefisien regresi variabel keaktifan mengikuti Organisasi Siswa Intra Sekolah (OSIS) sebesar0,39 artinya jika keaktifan mengikuti Organisasi Siswa Intra Sekolah (OSIS) mengalami peningkatan $1 \%$ maka hasil belajarnya akan mengalami peningkatan sebesar $0,39 \%$

3) Tanda (+) pada koefisien regresi menunjukkan adanya pengaruh positif variabel $\mathrm{X}$ terhadap variabel $\mathrm{Y}$ dan juga menunjukkan adanya peningkatan variabel $\mathrm{Y}$ yang didasarkan pada perubahan variabel $\mathrm{X}$.

Dari output yang diolah melalui SPSS16 dapat diketahui bahwa $\mathrm{t}_{\text {hitung }}=2.981$ dengan nilai signifikan sebesar 0,337 pada taraf signifikasi $5 \%$ uji dua pihak dan $\mathrm{dk}=\mathrm{n}-1=25-1=24$. Maka diperoleh $t_{\text {tabel }}$ sebesar 2,064, maka dapat disimpulkan bahwa Ho ditolak dan Ha diterima, yang berarti terdapat pengaruh yang signifikan antara keaktifan mengikut Organisasi Siswa Intra Sekolah terhadap hasil belajar siswa. Keaktifan mengikuti Organisasi Siswa 
Intra Sekolah (OSIS) terhadap hasil belajar siswa sebesar 4\% dan sisanya yaitu $96 \%$ dipengaruhi oleh faktor lain yang tidak diteliti dalam penelitian ini.

\section{Simpulan}

Penelitian ini bertujuan untuk mengetahui pengaruh keaktifan mengikuti Organisasi Siswa Intra Sekolah (OSIS) terhadap hasil belajar siswa pada mata pelajaran pendidikan agama Islam di Sekolah Menengah Atas Negeri 09 Kota Bengkulu. Hasil penelitian tersebut dapat dilihat sebagai berikut:

1. Berdasarkan variabel $X$ yaitu keaktifan mengikuti Organisasi Siswa Intra Sekolah dengan 30 item pertanyaan, dapat diketahui bahwa faktor yang paling mempengaruhi hasil belajar siswa adalah item nomor 23 sebesar $77 \%$ bahwa siswa mengikuti kegiatan OSIS dengan baik.

2. Berdasarkan variabel $\mathrm{Y}$ yaitu hasil belajar siswa, dengan nilai rata-rata yaitu 85, 08 dengan ketuntasan mencapai $100 \%$.

3. Berdasarkan hasil penelitian dan perhitungan yang sudah diolah menggunakan SPSS16 didapatkan hasil uji analisis regresi Linier sederhana dengan persamaan $\mathrm{Y}=88,835+0,39 \mathrm{X}$. Adapun koefisien regresi variabel mengikuti Organisasi Siswa Intra Sekolah (X) sebesar 0,39 artinya jika keaktifan mengikuti Organisasi Siswa Intra Sekolah mengalami peningkatan 1\%, maka hasil belajar akan mengalami peningkatan sebesar 0,39\%. Tanda (+) pada koefisien regresi menunjukkan adanya pengaruh positif variabel $\mathrm{X}$ terhadap variabel $\mathrm{Y}$ dan juga menunjukkan adanya peningkatan variabel $\mathrm{Y}$ yang didasarkan pada perubahan variabel X.

4. Berdasarkan kriteria yang telah dibahas sebelumnya Ha dapat diterima jika $t_{\text {hitung }}$ lebih besar dari $t_{\text {tabel }}$ dengan taraf signifikan $5 \%$ uji dua pihak dan $\mathrm{dk}=\mathrm{n}-1=25-1=24$. Dari pengujian tersebut diperoleh $t_{\text {tabel }}$ sebesar 2,064 dan $t_{\text {hitung }}$ sebesar 2,981 pada taraf signifikan 0,05 . Berdasarkan hasil tersebut $t_{\text {hitung }}$ lebih besar daripada $t_{\text {tabel. }}$. Maka dapat disimpulkan bahwa Ha diterima dan Ho ditolak sehingga terdapat pengaruh keaktifan mengikuti Organisasi Siswa Intra Sekolah (X) terhadap hasil belajar siswa (Y).

5. Berdasarkan uji koefisien determinasi $\left(\mathrm{R}^{2}\right)$, koefisien bernilai positif berarti terdapat hubungan yang positif antara keaktifan 
mengikuti Organisasi Siswa Intra Sekolah (X) berpengaruh secara signifikan terhadaphasil belajar siswa (Y). Semakin besar pengaruh keaktifan mengikuti Organisasi Siswa Intra Sekolah maka hasil belajar siswa akan semakin baik. Berdasarkan nilai $\mathrm{R}$ Square sebesar 0,040, maka dapat dilihat bahwa kontribusi keaktifan mengikuti OSIS dalam mempengaruhi hasil belajar siswa sebesar $4 \%$ sementara sisanya $96 \%$ dipengaruhi oleh faktor lain yang tidak diteliti dalam penelitian ini. 


\section{DAFTAR PUSTAKA}

Aziz, F., Nurjanah, F., \& Sari, D. P. 2017. Aktualisasi TTB (Teori Taksonomi Bloom) Melalui Drama Kepahlawanan Guna Penanaman Pendidikan Karakter Pada Peserta Didik. FKIP EProceeding PBSI Universitas Jember.

Chandra, P. 2020. Peran Pondok Pesantren dalam Membentuk Karakter Bangsa Santri di Era Disrupsi. Belajea; Jurnal Pendidikan Islam. https://doi.org/10.29240/belajea.v5i2.1497

Crossman, A. 2020. Purposive Sampling - Definition and Types. In Thoughtco.

Harahap, N., \& Lubis, S. D. 2019. Metodologi Penelitian Kuantitatif. In Journal of Chemical Information and Modeling.

Jenilan, J. 2018. Filsafat Pendidikan. EL-AFKAR : Jurnal Pemikiran Keislaman Dan Tafsir Hadis. https://doi.org/10.29300/jpkth.v7i1.1588

Kemendikbud. 2013. UU SISDIKNAS Nomor 20 Tahun 2003. KEMENDIKBUD.

Kunandar. 2015. Penilaian Autentik (Penilaian Hasil Belajar Pesrta Didik Berdasarkan Kurikulum 2013. In Jurnal Evaluasi Pendidikan.

Marhayati, N., Chandra, P., \& Fransisca, M. 2020. Pendekatan Kognitif Sosial pada Pembelajaran Pendidikan Agama Islam. DAYAH: Journal of Islamic Education, 3(2), 250-270.

Mochammad Arif Budiman. 2017. Pendidikan Agama Islam. Banjarbaru: Grafika Wangi Kalimantan.

Nafeesa, N. 2018. Faktor-Faktor yang Mempengaruhi Prokrastinasi Akademik Siswa yang Menjadi Anggota Organisasi Siswa Intra Sekolah. Anthropos: Jurnal Antropologi Sosial dan Budaya (Journal of Social and Cultural Anthropology). https://doi.org/10.24114/antro.v4i1.9884

Putrana, Y., Fathoni, A., \& Warso, M. M. 2016. Pengaruh Kepuasan Kerja dan Komitmen Organisasi Terhadap Organizational Citizenship Behavior dalam Meningkatkan Kinerja Karyawan Pada PT. Gelora Persada Mediatama Semarang. Journal of Management.

Riadi, E. 2016. Statistika Penelitian (Analisis Manual dan IBM SPSS). In Statistika Penelitian (Analisis Manual dan IBM SPSS). 
Ricardo, R., \& Meilani, R. I. 2017. Impak Minat dan Motivasi Belajar Terhadap Hasil Belajar Siswa. Jurnal Pendidikan Manajemen Perkantoran. https://doi.org/10.17509/jpm.v2i2.8108

Sobirin, A. 2014. Organisasi dan Perilaku Organisasi. Budaya Organisasi, Pengertian, Makna Dan Aplikasinya.

Sugiyono. 2016. Metode Penelitian Kuantitatif Kualitataif dan Kombinasi (Mixed Methods). Journal of Chemical Information and Modeling.

Sugiyono. 2018. Metode Peneiltian Kuantitatif, Kualitatif dan R \& D. Bandung: Alfabeta.

Syafi'i, A., Marfiyanto, T., \& Rodiyah, S. K. 2018. Studi Tentang Prestasi Belajar Siswa dalam Berbagai Aspek dan Faktor yang Mempengaruhi. Jurnal Komunikasi Pendidikan. https://doi.org/10.32585/jkp.v2i2.114 